Pacific Journal of Mathematic 


\title{
RIESZ HOMOMORPHISMS AND POSITIVE LINEAR MAPS
}

\author{
C. T. TUCKER
}

It was shown in previous papers [C. T. Tucker, "Homomorphisms of Riesz spaces," Pacific J. Math., 55 (1974), 289-300, and "Concerning $\sigma$-homomorphisms of Riesz spaces," Pacific J. Math., 57 (1975), 585-590] that there is a large class $\beta$ of Riesz spaces with the property that if $L$ belongs to $\beta$ and $\phi$ is a Riesz homomorphism of $L$ into an Archimedean Riesz space then $\phi$ preserves the order limit of sequences. In this paper it is shown that if $L$ belongs to $\beta$ then every order bounded linear map of $L$ into an Archimedean, directed, partially ordered vector space is sequentially continuous. An application of this is made to the theory of Baire funtions. Further, some properties of those members of $\beta$ which are also normed Riesz spaces are considered.

This paper is a continuation and extension of Tucker [8] and [9]. The notation of Tucker [8] and [9] will be used.

The following theorem includes Theorem 19.8 of Nakano [5].

THEOREM 1. Suppose $L$ belongs to $\beta$. Then every order bounded linear map of $L$ into an Archimedean, directed, partially ordered vector space is sequentially continuous.

Proof. Suppose $E$ is a complete Riesz space and let $\mathscr{L}^{\sim}=$ $\mathscr{L}^{\sim}(L, E)$ be the complete Riesz space of all order bounded linear transformations of $L$ into $E$. If $f \in L$ and $T \in \mathscr{L}^{\sim}$, then denote by $\langle f, T\rangle$ the order bounded bilinear form $\langle f, T\rangle=T f$. The canonical imbedding of $L$ into $\mathscr{L}^{\sim}\left(\mathscr{L}^{\sim}(L, E), E\right)$ is a Riesz homomorphism. (A proof when $E=R$ is given in Kelley and Namioka [2], Section 23. The same argument holds when $R$ is replaced by any complete Riesz space.) Since $\mathscr{L}^{\sim}\left(\mathscr{L}^{\sim}(L, E), E\right)$ is Archimedean, it follows from the hypothesis that the imbedding preserves countable suprema and infima. Hence if $f_{n} \downarrow \theta$, then for every $T \in \mathscr{L}^{\sim}, T f_{n}=\left\langle f_{n}, T\right\rangle \downarrow \theta$ by definition of $\mathscr{L}^{\sim}$.

Suppose $E$ is only an Archimedean, directed, partially ordered vector space. There exists a one to one order continuous positive linear map $\lambda$ of $E$ into $\bar{E}$, its completion. If $T$ is an order bounded linear map of $L$ into $E$, then $\lambda T$ is an order bounded linear map of $L$ into the complete Riesz space $\bar{E}$ and thus $\lambda T$ is sequentially continuous. This implies that $T$ is sequentially continuous.

In view of the previous theorem the elements of $\beta$ will be said 
to have the sequential mapping continuity property, abbreviated the s.m.c. property.

In Tucker [7], property $c$ was defined. It was shown in Tucker [8] that if a Riesz space contained a point with property $c$ then it belonged to $\beta$. The following shows more clearly how property $c$ relates to other properties.

Definition. A point $x \geqq \theta$ has weak property $c$ if, whenever $\left\{h_{i}\right\}$ is a sequence such that $h_{i} \uparrow x$, there exists a subsequence $h_{i_{1}}$, $h_{i_{2}}, h_{i_{3}}, \cdots$ and a point $b$ such that $b \leqq \sum_{p=1}^{n} h_{i_{p}}$ for each positive integer $n$.

Clearly in the hypothesis of Theorem 3 of [8], property $c$ could be replaced by weak property $c$ with only a minor modification of the argument.

THEOREM 2. Suppose order convergence in $L$ is stable and $f \geqq \theta$. Then $f$ has weak property $c$.

Proof. Suppose $h_{i} \uparrow f$. Then $h_{i}^{-} \uparrow \theta$. Since order convergence is stable there exists a point $g$ and a sequence $\left\{c_{i}\right\}$ of real numbers converging to 0 such that $c_{i} g \leqq h_{i}^{-}$. Let $\left\{c_{i_{p}}\right\}$ be a subsequence of $\left\{c_{i}\right\}$ such that $c_{i_{p}}<1 / 2^{p}$. Then $\sum_{p=1}^{n} h_{i}^{-} \geqq \sum_{p=1}^{n} c_{i_{p}} g \geqq \sum_{p=1}^{n} 1 / 2^{p} g \geqq g$.

Suppose each of $\Omega$ and $\Omega^{\prime}$ is a linear lattice of functions on a set $X$ containing the constant functions. Denote by $B_{1}(\Omega)$ (the first Baire class of $\Omega$ ) the family of all pointwise limits of sequences from $\Omega$ and by $L S(\Omega)$ the family of all pointwise limits of nondecreasing sequences from $\Omega$. For a recent survey of the properties of Baire functions, see Mauldin [4].

Lemma 3. Pointwise monotone convergence in $B_{1}(\Omega)$ is equivalent to monotone order convergence. (In the sense that $f_{i} \downarrow f \in B_{1}(\Omega)$ in order convergence if and only if it does in pointwise convergence also.)

Proof. Clearly pointwise convergence implies order convergence. Suppose $f_{1} \geqq f_{2} \geqq f_{3} \geqq \cdots \geqq \theta, f_{i} \in B_{1}(\Omega)$, and $\wedge f_{i}=\theta$. There exists a sequence $g_{1} \geqq g_{2} \geqq g_{3} \geqq \cdots \geqq \theta$ such that $g_{i} \in L S(\Omega)$ and the pointwise limit of $\left\{g_{i}\right\}$ is the same as the pointwise limit of $\left\{f_{i}\right\}$. Suppose there exists an $x \in X$ and $\varepsilon>0$ such that $g_{i}(x)>\varepsilon$ for every positive integer $i$. There exists a point $h_{i} \in \Omega$ such that $g_{i} \geqq h_{i} \geqq \theta$ and $h_{i}(x)=\varepsilon . \quad$ Let $k_{i}=\min _{p \geqq i}\left\{h_{i}\right\} . \quad$ Then $k_{1} \geqq k_{2} \geqq k_{3} \geqq \cdots \geqq \theta, k_{i} \in \Omega$, $k_{i} \leqq g_{i}$, and $k_{i}(x)=\varepsilon$. Let $j$ be the pointwise limit of $\left\{k_{i}\right\}$. Then $j \in B_{1}(\Omega), \quad g_{i} \geqq j$, and $j(x)=\varepsilon>0$, so that $j \neq \theta$. This is a contradiction. Thus $\left\{f_{i}\right\}$ converges pointwise to $\theta$. 
Proposition 4. The space $B_{1}(\Omega)$ contains a point with weak property $c$.

Proof. In view of Lemma 3, the proof of Theorem 6 of Tucker [9] holds.

COROLlaRY 5. An order bounded linear mapping from $B_{1}(\Omega)$ to $B_{1}\left(\Omega^{\prime}\right)$ is sequentially continuous (and thus preserves bounded pointwise convergence).

If " \|\| " is a norm on the Riesz space $L$ such that $\|f\| \leqq\|g\|$ if $|f| \leqq|g|$, then " \|\| " is called a Riesz norm on $L$ and $L$ is said to be a normed Riesz space. Also $L$ will be said to have property $(A, i)$ if $f_{i} \downarrow \theta$ implies $\left\|f_{i}\right\| \downarrow 0$.

The remainder of this paper will consider those members of $\beta$ which are also normed Riesz spaces.

THEOREM 6. Suppose $L$ is a normed Riesz space. Then, of the following conditions, (1) implies (2) and (2) implies (3). If $L$ is assumed to be norm complete then each two of the three conditions are equivalent. If $L$ is not assumed to be norm complete then the reverse implications do not hold.

(1) Order convergence in $L$ is stable.

(2) $L$ has the s.m.c. property.

(3) L has property $(A, i)$.

Proof. (1) implies (2) clearly. If $L$ has the s.m.c. property then every positive linear functional is sequentially continuous, thus by Corollary 24.3 of Luxemburg and Zaanen [3], $L$ has property $(A, i)$.

In the event that $L$ is norm complete and has property $(A, i)$, then order convergence implies norm convergence which implies relative uniform convergence and (1) holds.

For an example to show that (3) does not imply (2) if $L$ is not assumed to be norm complete take $L^{\infty}$ with the $L^{2}$ norm.

To show that (2) does not imply (1) in the absence of norm completeness consider the following example: Let $S$ be the set of all ordered pairs of positive integers. Let $L$ be the collection to which $f$ belongs only in case $f$ is a real valued function on $S$ with the property that there is a set $\omega$ which includes all but at most a finite number of positive integers such that if $k$ is a positive integer in $\omega, f(1, k), f(2, k) f(3, k), \cdots$ is a bounded number sequence and with the property that

$$
\sum_{p=1}^{\infty} \sum_{q=1}^{\infty} \frac{1}{2^{p}} \frac{1}{2^{q}}|f(p, q)|<\infty .
$$


The space $L$ is an order complete Riesz space and

$$
\|f\|=\sum_{p=1}^{\infty} \sum_{q=1}^{\infty} \frac{1}{2^{p}} \frac{1}{2^{q}}|f(p, q)|
$$

is a Riesz norm on $L$.

Suppose $M$ is an ideal which is relatively uniformly closed. Let $f$ be the l.u.b. of a countable subset $\alpha$ of $M$. The function which is equal to $f(i, j)$ at $(i, j)$ and zero elsewhere is in $M$. For each positive integer $k$ let $f_{k}(p, q)=f(p, q)$ if $k=q$ and zero otherwise. There exists a nondecreasing unbounded sequence of positive integers $\left\{c_{i}\right\}$ such that the function $g_{k}$ defined by $g_{k}(p, q)=c_{p} f_{k}(p, q)$ is in $L$. Thus $f_{k}$ is in $M$. Also, there exists a non-decreasing unbounded sequence of positive integers $\left\{d_{i}\right\}$ such that $h(p, q)=d_{q} f(p, q)$ is in $L$. Therefore $f$ is in $M$. By Corollary 4 of Tucker [9], $L$ has the s.m.c. property.

For each positive integer $i$, let $g_{\imath}$ be the function such that $g_{i}(p, q)=1$ if $p=i$ and $g_{i}(p, q)=0$ if $p \neq i$. Then $\left\{g_{i}\right\}$ is an orthogonal subset of $L$ whose supremum is the constant function 1 , but there is no nondecreasing unbounded positive number sequence $\left\{k_{i}\right\}$ such that $\left\{k_{2} g_{2}\right\}$ is bounded above. Thus order convergence is not stable in $L$.

The Riesz space $L$ is said to be almost $\sigma$-complete if $L$ is a Riesz subspace of a $\sigma$-complete space $K$ such that for every $\theta \leqq u \in K$ there exists a sequence $\left\{u_{n}\right\} \subseteq L$ with $\theta \leqq u_{n} \uparrow u$ in $K$. See Aliprantis and Langford [1] or Quinn [6] for some properties of almost $\sigma$-complete spaces.

Corollary 7. Suppose the normed Riesz space $L$ has s.m.c. property. Then every order bounded linear mapping of $L$ into an Archimedean, directed, partially ordered vector space preserves order convergence of nets if and only if $L$ is almost $\sigma$-complete.

Proof. Suppose $L$ is almost $\sigma$-complete. By Theorem 9.1 of Quinn [6], $L$ is order separable which implies that sequentially continuous maps are net continuous. On the other hand, if every sequentially continuous map is net continuous, then $L$ is order separable and therefore almost $\sigma$-complete.

The following theorem includes Theorem 5.1 of Zaanen [10] and Theorem 3 of Tucker [7].

THeOREM 8. Suppose $L$ has the s.m.c. property, is almost o-complete, and has a strong unit. Then $L$ is finite dimensional. 
Proof. Let $\left\{h_{i}\right\}$ be a countable orthogonal subset of $L^{+}$. Suppose $e$ is a strong unit of $L$. It may be assumed that for each positive integer $i, e \geqq h_{i}$. By Corollary 8.5 of Quinn [6], there exists a sequence $f_{n} \downarrow \theta$ such that $f_{n} \geqq\left|\sum_{i=1}^{n+p} h_{i}-\sum_{i=1}^{n} h_{i}\right|$ for each positive integer $p$. Thus $f_{n}$ is an upper bound of $\left\{h_{i}\right\}_{i=n+1}^{\infty}$. It may be assumed that for each positive integer $n, f_{n} \leqq e$. Let $g_{n}=e-$ $\left(f_{n} \vee\left(\bigvee_{i=1}^{n} h_{i}\right)\right)$. Then $e \geqq g_{n+1} \geqq g_{n}$.

Let $Q$ be the set to which $f$ belongs only in case $f \in L^{+}, f \leqq e$, and if $\varepsilon>0$ there exists a positive integer $n$ such that

$$
\bigwedge_{p=1}^{\infty}\left(f-\varepsilon e-\sum_{i=1}^{n} h_{i}-g_{p}\right)^{+}=\theta .
$$

Let $M$ be the set to which $f$ belongs only in case there is a positive number $c$ such that $c|f| \in Q$. To show that $M$ is an ideal, suppose that $f$ and $g$ are in $M$. Now $|f+g| \leqq|f|+|g|=|f| \vee|g|+|f| \wedge$ $|g| \leqq 2(|f| \vee|g|) \in M$. So that $f+g$ is in $M$. The other properties of an ideal follow easily.

Note that $e=\vee h_{i}+\vee g_{i}$, but since $e-\varepsilon e-g_{p}=\left(f_{p} \vee\left(\bigvee_{i=1}^{p} h_{i}\right)\right)-$ $\varepsilon e \geqq \sum_{i=1}^{n} h_{i}-\varepsilon e$ for each positive integer $n, e$ is not in $M$ and $M$ is not a $\sigma$-ideal.

Suppose $d_{i} \downarrow 0,\left\{f_{\imath}\right\}$ is a sequence of points of $M$, and $f$ is a point of $L$ such that $\left|f-f_{i}\right| \leqq d_{i} e$. Let $\varepsilon>0$ and $d_{i}<\varepsilon / 2$. Then $f_{i}+\varepsilon / 2 e \geqq f$ and $f_{i}-\varepsilon / 2 e \geqq f-\varepsilon e$. There exists a positive integer $n$ such that $\Lambda_{p=1}^{\infty}\left(f_{i}-\varepsilon / 2 e-\sum_{i=1}^{n} h_{i}-g_{p}\right)^{+}=\theta$. Thus,

$$
\bigwedge_{p=1}^{\infty}\left(f-\varepsilon e-\sum_{i=1}^{n} h_{i}-g_{p}\right)^{+}=\theta,
$$

$f$ belongs to $M$, and $M$ is uniformly closed. This is a contradiction.

In Theorem 8, the s.m.c. property cannot be replaced by property $(A, i)$ as the first example in Theorem 6 shows. The following example shows that the almost $\sigma$-completeness can not be dropped.

ExAmple 9. Let $X$ be an uncountable set and let $L$ be the space of all real valued functions on $X$ that are constant except possibly on a finite subset of $X$. Then $L$ has the principal projection property but is not almost $\sigma$-complete. Also $L$ is infinite dimensional, has a strong unit, and has the s.m.c. property since the constant function 1 has weak property $c$.

\section{REFERENCES}

1. C. D. Aliprantis and Eric Langford, Almost $\sigma$-Dedekind complete Riesz spaces and the main inclusion theorem, Proc. Amer. Math. Soc., 44 (1974) 421-426.

2. J. L. Kelley and I. Namioka, Linear Topological Spaces, Van Nostrand, 1963. 
3. W. A. J. Luxemburg and A. C. Zaanen, Notes on Banach function spaces VII, Nederl. Akad. Wetensch. Proc. Ser. A, 66 (1963), 669-681.

4. R. Daniel Mauldin, Baire functions, Borel sets, and ordinary function systems, Advances in Math., 12 (1974), 418-450.

5. H. Nakano, Linear Lattices, Wayne State University Press, 1966.

6. J. Quinn, Intermediate Riesz spaces, Pacific J. Math., 56 (1975), 225-263.

7. C. T. Tucker, On a theorem concerning Baire functions, Proc. Amer. Math. Soc., 41 (1973), 173-178.

8. — Homomorphisms of Riesz spaces, Pacific J. Math., 55 (1974), 289-300.

9. — Concerning o-homomorphisms of Riesz spaces, Pacific J. Math., 57 (1975), 585-590.

10. A. C. Zaanen, Stability of order convergence and regularity in Riesz spaces, Studia Math., 31 (1968), 159-172.

Received April 6, 1976 and in revised form November 1, 1976.

UNIVERSITY OF HOUSTON

Houston, TX 77004 


\section{PACIFIC JOURNAL OF MATHEMATICS}

\section{EDITORS}

RICHARD ARENS (Managing Editor)

University of California

Los Angeles, CA 90024

R. A. BEAUMONT

University of Washington

Seattle, WA 98105

C. C. Moore

University of California

Berkeley, CA 94720

\section{J. DugundJI}

Department of Mathematics

University of Southern California

Los Angeles, CA 90007

R. Finn and J. Milgram

Stanford University

Stanford, CA 94305

\section{ASSOCIATE EDITORS}

\section{E. F. BECKENBACH}

B. H. NEUMANN

F. WoLF

K. YOSHIDA

\section{SUPPORTING INSTITUTIONS}

\author{
UNIVERSITY OF BRITISH COLUMBIA \\ CALIFORNIA INSTITUTE OF TECHNOLOGY \\ UNIVERSITY OF CALIFORNIA \\ MONTANA STATE UNIVERSITY \\ UNIVERSITY OF NEVADA \\ NEW MEXICO STATE UNIVERSITY \\ OREGON STATE UNIVERSITY \\ UNIVERSITY OF OREGON \\ OSAKA UNIVERSITY
}

\author{
UNIVERSITY OF SOUTHERN CALIFORNIA \\ STANFORD UNIVERSITY \\ UNIVERSITY OF HAWAII \\ UNIVERSITY OF TOKYO \\ UNIVERSITY OF UTAH \\ WASHINGTON STATE UNIVERSITY \\ UNIVERSITY OF WASHINGTON \\ AMERICAN MATHEMATICAL SOCIETY
}

The Supporting Institutions listed above contribute to the cost of publication of this Journal, but they are not owners or publishers and have no responsibility for its content or policies.

Mathematical papers intended for publication in the Pacific Jaurnal of Mathematics should be in typed form or offset-reproduced, (not dittoed), double spaced with large margins. Please do not use built up fractions in the text of your manuscript. You may however, use them in the displayed equations. Underline Greek letters in red, German in green, and script in blue. The first paragraph or two must be capable of being used separately as a synopsis of the entire paper. Items of the bibliography should not be cited there unless absolutely necessary, in which case they must be identified by author and Journal, rather than by item number. Manuscripts, in triplicate, may be sent to any one of the editors. Please classify according to the scheme of Math. Reviews, Index to Vol. 39. All other communications should be addressed to the managing editor, or Elaine Barth, University of California, Los Angeles, California, 90024.

The Pacific Journal of Mathematics expects the author's institution to pay page charges, and reserves the right to delay publication for nonpayment of charges in case of financial emergency

100 reprints are provided free for each article, only if page charges have been substantially paid. Additional copies may be obtained at cost in multiples of 50 .

The Pacific Journal of Mathematics is issued monthly as of January 1966. Regular subscription rate: $\$ 7200$ a year (6 Vols., 12 issues). Special rate: $\$ 36.00$ a year to individual members of supporting institutions.

Subscriptions, orders for back numbers, and changes of address should be sent to Pacific Journal of Mathematics, 103 Highland Boulevard, Berkeley, California, 94708.

PUBLISHED BY PACIFIC JOURNAL OF MATHEMATICS, A NON-PROFIT CORPORATION

Printed at Kokusai Bunken Insatsusha (International Academic Printing Co., Ltd.). 8-8, 3-chome, Takadanobaba, Shinjuku-ku, Tokyo 160, Japan.

Copyrit (C) 1975 by Pacific Journal of Mathematics Manufactured and first issued in Japan 


\section{Pacific Journal of Mathematics \\ Vol. 69, No. $2 \quad$ June, 1977}

Carol Alf and Thomas Alfonso O'Connor, Unimodality of the Lévy spectral

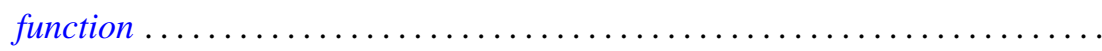

S. J. Bernau and Howard E. Lacey, Bicontractive projections and reordering of

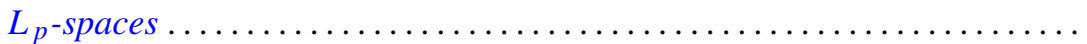

Andrew J. Berner, Products of compact spaces with bi-k and related spaces..... 303

Stephen Richard Bernfeld, The extendability and uniqueness of solutions of ordinary differential equations ...............................

Marilyn Breen, Decompositions for nonclosed planar m-convex sets ..........

Robert F. Brown, Cohomology of homomorphisms of Lie algebras and Lie

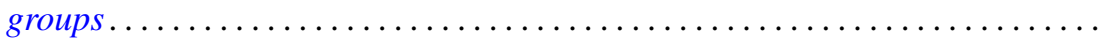

Jack Douglas Bryant and Thomas Francis McCabe, A note on Edelstein's iterative test and spaces of continuous functions ....................

Victor P. Camillo, Modules whose quotients have finite Goldie dimension ....... 333

David Downing and William A. Kirk, A generalization of Caristi's theorem with

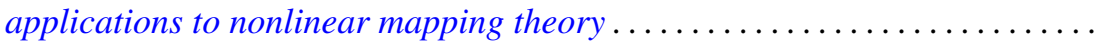

Daniel Reuven Farkas and Robert L. Snider, Noetherian fixed rings ...........

Alessandro Figà-Talamanca, Positive definite functions which vanish at

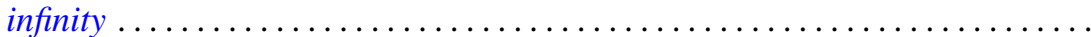

Josip Globevnik, The range of analytic extensions .................. 365

André Goldman, Mesures cylindriques, mesures vectorielles et questions de

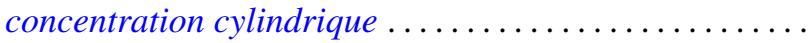

Richard Grassl, Multisectioned partitions of integers..........

Haruo Kitahara and Shinsuke Yorozu, A formula for the normal part of the

Laplace-Beltrami operator on the foliated manifold .... .

Marvin J. Kohn, Summability $R_{r}$ for double series .........

Charles Philip Lanski, Lie ideals and derivations in rings with involution ..

Solomon Leader, A topological characterization of Banach contractions . .

Daniel Francis Xavier O’Reilly, Cobordism classes of fiber bundles . .

James William Pendergrass, The Schur subgroup of the Brauer group . .

Howard Lewis Penn, Inner-outer factorization of functions whose Fourier series

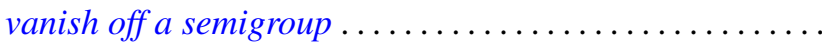

501

William T. Reid, Some results on the Floquet theory for disconjugate definite

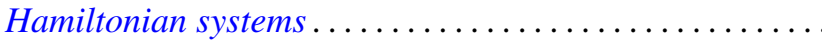

Caroll Vernon Riecke, Complementation in the lattice of convergence

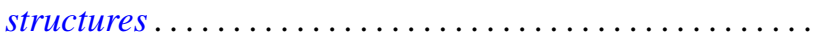

Louis Halle Rowen, Classes of rings torsion-free over their centers ......... 527

Manda Butchi Suryanarayana, A Sobolev space and a Darboux problem ....... 535

Charles Thomas Tucker, II, Riesz homomorphisms and positive linear maps.... 551

William W. Williams, Semigroups with identity on Peano continua ........... 557

Yukinobu Yajima, On spaces which have a closure-preserving cover by finite 